Original Research Article

\title{
Assessment of cost effectiveness of antihistaminics in allergic rhinitis patients in rural region by Nasal cytology: a simple and inexpensive tool
}

\author{
Ganesh S. Pentewar*, Ranjit J. Wagh, Aparna S. Chincholkar
}

Department of Pharmacology, MIMER Medical College, Talegaon Dabhade, Maharashtra, India

Received: 24 April 2018 Accepted: 09 May 2018

*Correspondence to: Dr. Ganesh S. Pentewar, Email: drpentewarganesh@ gmail.com

Copyright: (C) the author(s), publisher and licensee Medip Academy. This is an openaccess article distributed under the terms of the Creative Commons Attribution NonCommercial License, which permits unrestricted noncommercial use, distribution, and reproduction in any medium, provided the original work is properly cited.

\begin{abstract}
Background: This study was to assess the usefulness of nasal smear as a quick, easy and inexpensive diagnostic method for allergic rhinitis and for assessment of the cost effectiveness of antihistaminics.

Methods: This study was conducted in rural setting of tertiary care hospital. Nasal smears were taken from 52 patients with a clinical history of nasal allergy having nasal congestion score of at least 3 or more. Nasal smears were stained with Hematoxilin-Eosin and examined by pathologists.

Results: A total of 52 patients 13 in each groups of the age group 18 to 65 years (Mean age, $33.73 \pm 10.23$ years); $48.08 \%$ are Female and $51.92 \%$ are Male were randomized and received either Cetirizine, Levocetirizine, Loratadine, or Fexofenadine over a period of one week. The association of eosinophil before and after the treatment was obtained using logistic regression analysis for each treatment separately. Eosinophil is marginally associated with Cetirizine before and after treatment.

Conclusions: Evaluation of eosinophils in nasal smear is an insensitive but cheaper test for the diagnosis of allergic rhinitis and use as a simple tool for comparison of cost effectiveness among commonly used oral antihistaminics. pharmacoeconomic analysis of present comparative clinical study shows that cetirizine is a better choice in comparison with levocetrizine, loratidine and fexofenadine due to its cost effectiveness.
\end{abstract}

Keywords: Allergic rhinitis, Antihistaminics, Cost effectiveness, Eosinophilia, Nasal cytology

\section{INTRODUCTION}

Allergic rhinitis (AR) is an IgE-mediated hypersensitivity reaction of nasal mucosa which is characterized by sneezing, itching, watery nasal discharge and a sensation of nasal obstruction. A characteristic feature of allergic inflammation is local accumulation of inflammatory cells including $\mathrm{T}$ lymphocytes, mast cells, eosinophils, basophils and neutrophils. ${ }^{1}$ Release of various mediators from these cells is responsible for the symptoms of allergic rhinitis. Accumulation of additional inflammatory cells such as eosinophils and $\mathrm{T}$ cells occurs in response to various chemokines. These inflammatory cells can be easily identified in nasal mucosa or secretions by performing nasal biopsies and then, preparing nasal smears to confirm the diagnosis of allergic rhinitis. Moreover, these methods are simple, reproducible, easy to perform and cost effective as compared to other diagnostic tests for allergic rhinitis., ${ }^{2,3}$

The present study was planned to evaluate the diagnostic value of nasal smear as a simple, non-invasive and inexpensive method for diagnosing allergic rhinitis and used as a simple tool for comparing cost effectiveness among commonly used oral antihistaminic. Antihistaminic are effective in patients with allergic rhinitis having eosinophilia. When antihistaminic are given continuously 
for seven days, Clinical improvement is accompanied by decreases in numbers of effector cells in target organs eosinophil. In this research we explore correlation of eosinophilia and antihistaminic therapy for allergic rhinitis. Our expectation is that a greater understanding of the underlying mechanisms of allergens will identify potential biomarkers that could predict or monitor the response to treatment. The nasal mucosa is the most accessible for the non-invasive study part of the respiratory system. The nasal cytology is a research method evaluating cells located within it, and it is mainly used as an additional test in allergic rhinitis. This method allows to assess the pathophysiological changes occurring in the nasal mucosa and monitor response to applied treatment and thus has both diagnostic and therapeutic values. An extremely precious feature of this research is its noninvasiveness and painlessness as it does not require any anaesthesia, and it is cheap and simple to make.

The aim of this study was to evaluate the cytological picture of nasal mucosa in allergic rhinitis and their correlation with antihistaminic treatment. In addition, the objective was also to determine the suitability of the nasal mucosa for the diagnosis of allergic rhinitis and assessment of cost effectiveness of antihistaminic in allergic rhinitis patients.

\section{METHODS}

The study enrolled a total of 52 allergic rhinitis patients. All patients enrolled in the study were patients of the Department of otorhinolaryngology, MIMER medical college, Talegaon Dabhade. The study was approved by the Institutional Ethical Committee (IEC). In order to ensure better reliability of the results, only patients clinically diagnosed with allergic rhinitis were eligible on the basis of nasal congestion score. They are divided into four different groups as per antihistaminic treatment.

- Group I consisted of a total of 13 patients, including 6 male and 7 females who received Ceterizine.

- Group II consisted of a total of 13 patients, including 4 male and 9 females who received Levoceterizine.

- $\quad$ Group III consisted of a total of 13 patients, including 7 male and 6 females who received Loratidine.

- Group IV consisted of a total of 13 patients, including 10 male and 3 females who received fexofenadine.

Exclusion criteria for patients in all groups, participating in the study were current respiratory tract infection, Patients with history of hypersensitivity to antihistaminics. Concomitant medication that could affect the efficacy of study drugs. chronic use of inhaled or systemic corticosteroids, Pregnant or lactating women, usage of nasal corticosteroids within 14 days, usage of antihistamines within 14 days preceding the survey. Each test was preceded by obtaining informed consent from the patient, In the case of the examination in the nasal cavity of the secretions, the sample was taken after purging the nose. In each patient, the material for cytological examination has been collected from the middle third of the inferior turbinate. The samples were taken from one nasal cavity with nasal scraping method (using a nasal curette) and then transferred to a microscopic slide. The samples were spread onto a slide glass, air-dried, fixed, and stained with Haematoxylin and Eosin stain (Merck Limited). The samples were then evaluated for the presence or absence of eosinophil by examining $45 \mathrm{x}$ magnification high power fields (HPFs) with Nikon Eclipse 50 I Pentahead microscope (Nikon Corporation, Japan). ${ }^{4}$ The analysis was based on identifying in successive fields of the presence of particular cell types: ciliated and non-ciliated columnar cells, mucous (goblet) cells, basal, and squamous cells, neutrophils and eosinophils. No adverse effects were observed in any patient which could result from the research itself.

\section{Efficacy variable}

- Mean change in \% of eosinophil in nasal smear from Baseline to End of treatment.

- Cost effectiveness analysis. . $^{5-7}$

Statistical analysis was performed using the statistical software Microsoft SPSS 19.0. (SPSS Inc., Chicago, USA). Data was summarized using Mean, Median and Standard Deviation. Mean change in Nasal smear for eosinophil before and after treatment were done. Statistical differences were considered statistically significant for which the level of statistical significance fulfilled the condition of $\mathrm{p}<0.05$. Logistic regression analysis and odds ratio were used for analysis of qualitative data. The statistician was blinded to the groups during analysis.

\section{RESULTS}

A total of 52 patients 13 in each groups of the age group 18 to 65 years (Mean age, $33.73 \pm 10.23$ years); $48.08 \%$ are Female and $51.92 \%$ are Male were randomized and received either Cetirizine, Levocetirizine, Loratadine, or Fexofenadine over a period of one week. Mean compliance with treatment was $100 \%$ for all four treatment groups. The baseline demographic data and clinical characteristics of all 52 patients participated in this study have been compared in the Table 1 . The association of eosinophil before and after the treatment was obtained using logistic regression analysis for each treatment separately in the Table 2. Eosinophil is marginally associated with Cetirizine before and after treatment and has been have been compared in the Figure 1 and Figure 2.

\section{Average cost-effectiveness calculations}

The average cost effectiveness $=$ Net Cost $($ Rupees ₹) $/$ Net Health Benefit $=₹ / \%$ Mean change in nasal smear eosinophil

The average cost effectiveness of intervention for Cetirizine $=$ Net Cost $/$ Net Health Benefit $=₹ 26.25 / 0.4=$ ₹ 65.625 per cure 
Table 1: Comparison of demographic data and clinical characteristics of the patients participated in the study $(\mathbf{n}=52)$.

\begin{tabular}{|c|c|c|c|c|c|c|}
\hline Parameters & $\begin{array}{l}\text { Cetirizine } \\
n=13\end{array}$ & $\begin{array}{l}\text { Levocetirizine } \\
\mathrm{n}=13\end{array}$ & $\begin{array}{l}\text { Loratadine } \\
n=13\end{array}$ & $\begin{array}{l}\text { Fexofenadine } \\
n=13\end{array}$ & $\mathbf{F}$ & $\mathbf{p}^{*}$ \\
\hline Age (years) & $31.85 \pm 9.45$ & $39.38 \pm 14.39$ & $32 \pm 1.011$ & $31.69 \pm 7.22$ & 1.858 & 0.149 \\
\hline $\begin{array}{l}\text { Sex } \\
\text { Male }(\%) \\
\text { Female }(\%)\end{array}$ & $\begin{array}{l}6(46.16 \%) \\
7(53.84 \%)\end{array}$ & $\begin{array}{l}4(30.77 \%) \\
9(69.23 \%)\end{array}$ & $\begin{array}{l}7(53.84 \%) \\
6(46.16 \%)\end{array}$ & $\begin{array}{l}10(76.92 \%) \\
3(23.08 \%)\end{array}$ & & \\
\hline NCS & $4.46 \pm 0.66$ & $3.87 \pm 0.68$ & $4 \pm 0.82$ & $4.15 \pm 0.55$ & 1.905 & 0.141 \\
\hline
\end{tabular}

The values are expressed as mean $\pm \mathrm{SD}, \mathrm{NCS}=$ Nasal congestion score, *one way ANOVA

Table 2: Comparison of Eosinophil in Nasal secretion smear baseline and at the end of each treatment.

\begin{tabular}{|c|c|c|c|c|c|c|}
\hline Groups(n=13) & Baseline & \multicolumn{2}{|c|}{ End of treatment } & Total & Odds & p \\
\hline & & Absent & Present & & & \\
\hline \multirow{2}{*}{ Cetirizine } & Absent & 7 & 2 & 9 & \multirow{2}{*}{10.5} & \multirow{2}{*}{0.094} \\
\hline & Present & 1 & 3 & 4 & & \\
\hline Total & & 8 & 5 & 13 & & \\
\hline \multirow{2}{*}{ Levocetirizine } & Absent & 5 & 2 & 7 & \multirow{2}{*}{2.5} & \multirow{2}{*}{0.433} \\
\hline & Present & 3 & 3 & 6 & & \\
\hline Total & & 8 & 5 & 13 & & \\
\hline \multirow{2}{*}{ Loratadine } & Absent & 5 & 3 & 8 & \multirow{2}{*}{6.67} & \multirow{2}{*}{0.155} \\
\hline & Present & 1 & 4 & 5 & & \\
\hline Total & & 6 & 7 & 13 & & \\
\hline \multirow{2}{*}{ Fexofenadine } & Absent & 2 & 4 & 6 & \multirow{2}{*}{5.79} & \multirow{2}{*}{0.237} \\
\hline & Present & 2 & 5 & 7 & & \\
\hline Total & & 4 & 9 & 13 & & \\
\hline
\end{tabular}

$\mathrm{n}=13$ patient

The association of eosinophil before and after the treatment was obtained using logistic regression analysis for each treatment separately. Eosinophil is marginally associated with Cetirizine before and after treatment.

Table 3: Pharmacoeconomic assessments (cost effectiveness analysis).

\begin{tabular}{|c|c|c|c|c|}
\hline Methods & Cetirizine & Levocetirizine & Loratidine & Fexofenadine \\
\hline \multirow{4}{*}{$\begin{array}{l}\text { Method } 1 \\
\text { Cost consequence } \\
\text { Analysis (CCA) }\end{array}$} & \multicolumn{4}{|c|}{ Net Cost (at the end of 1 week treatment) } \\
\hline & $₹ 26.25$ & ₹ 29.46 & ₹ 39.84 & ₹ 75.58 \\
\hline & \multicolumn{4}{|c|}{ Net health benefit (\% Mean change in nasal smear eosinophil) } \\
\hline & 40 & 40 & 42.85 & 44.45 \\
\hline \multirow{3}{*}{$\begin{array}{l}\text { Method } 2 \\
\text { Average Cost } \\
\text { Effectiveness Ratios } \\
\text { (net cost/ net health benefit) }\end{array}$} & & & & \\
\hline & $₹ 26.25 / 0.4$ & ₹29.46 / 0.4 & ₹39.84 / 0.4285 & ₹75.58 / 0.4445 \\
\hline & $=₹ 65.625$ per cure & $=₹ 73.65$ per cure & $=₹ 92.97$ per cure & $=₹ 170.03$ per cure \\
\hline
\end{tabular}

Using this same means of calculation, the average cost effectiveness for intervention has been done for other treatment groups. The average cost effectiveness of intervention for Levocetirizine was ₹ 73.65 per cure, Loratadine was ₹ 92.97 per cure and for Fexofenadine was ₹ 170.03 per cure (Table 3).

\section{Cost effectiveness analysis}

In Noncompeting choice, Cetirizine should be covered first because it has the best (lowest) cost-effectiveness ratio compared to the other interventions (i.e. ₹ $65.625 / \%$ effect vs ₹ 73.65 / \% effect or ₹ 92.97 / \% effect or ₹ 170.03 / \% effect). This would be a more efficient way of spending money rather than starting with one of the other interventions that has a higher average cost-effectiveness ratio without any additional benefit (Table 3 ).

In competing choice method of cost-effectiveness analysis the incremental cost-effectiveness ratio has been done. This would allow to determine the marginal or incremental cost for an additional unit of health benefit when choosing between different interventions. But in this study there were no any additional health benefit by choosing other 
antihistaminics vs cetirizine so incremental costeffectiveness ratio has not been done. ${ }^{7}$

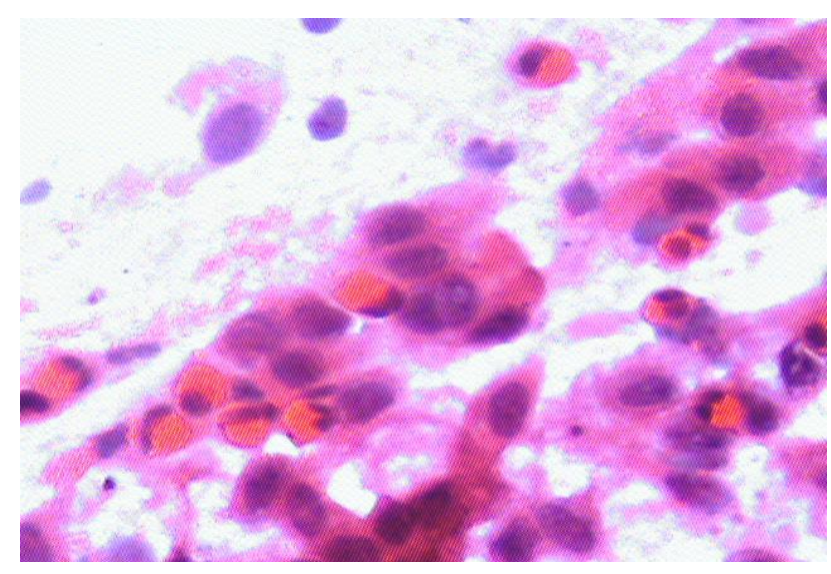

Figure 1: Microphotograph of nasal smear at baseline of an AR patient (ABT13, FL308/13) receiving Cetirizine, showing clumps of mucosal epithelial cells along with eosinophils ( $\mathrm{H}$ and $\mathrm{E} 40 \mathrm{X}$ ).

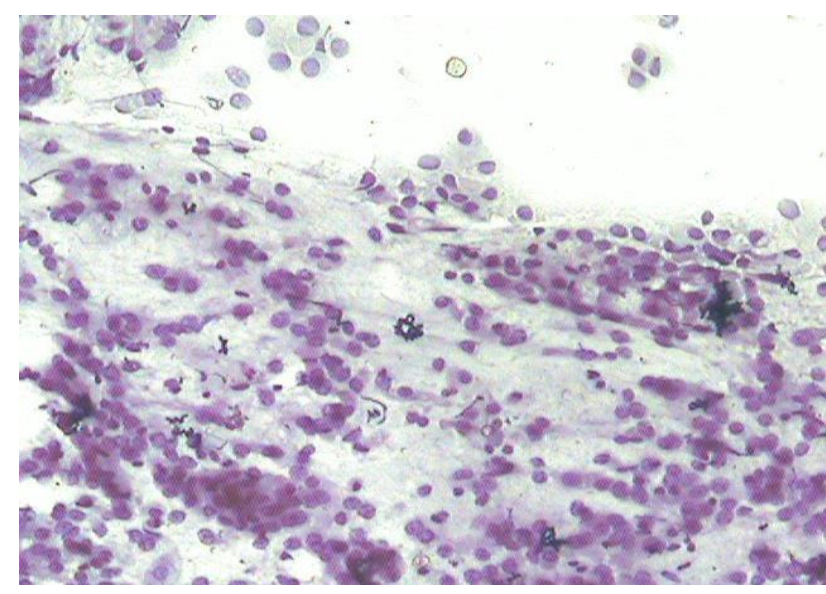

Figure 2: Microphotograph of nasal smear at the end of treatment of an AR patient (AAT13, FL326/13) receiving Cetirizine, showing clumps of mucosal epithelial cells, no eosinophil seen (H and E 10X).

\section{DISCUSSION}

The demographic characteristics of the study participants and the baseline symptom scores i.e. Nasal Congestion Score prior to dosing were comparable among the four treatment groups (Table 1). Rhinitis is a heterogeneous disorder characterized by one or more of the following nasal symptoms: sneezing, itching, rhinorrhea, and/or nasal congestion. Studies reflect a more accurate prevalence of rhinitis but are likely to continue to underreport this disease. ${ }^{8,9}$ Approximately $50 \%$ of all cases of rhinitis are caused by an $\mathrm{IgE}$ mediated reaction to allergens. In this case symptoms arise as a result of local inflammation induced by aeroallergens such as pollens, molds, animal dander and house dust mites. The immune response involves the release of inflammatory mediators and the activation and recruitment of different inflammatory cells to the nasal mucosa. ${ }^{10}$ Infiltration of inflammatory cells is evident in both seasonal and perennial form, although the magnitude of these cellular changes is somehow different in seasonal and perennial allergic rhinitis. ${ }^{11}$ Although the type of infiltrating cells and pattern of inflammation is varied among different studies but generally accepted, allergic rhinitis (AR) is characterized the recruitment of eosinophils into the nasal mucous. Increased numbers of eosinophils are reported within nasal lavage. ${ }^{12,13}$ secretions, smear, brush and biopsy samples in perennial AR compared with healthy nasal mucous. Nasal cytological examination for these cells not only establishes the diagnosis of allergic rhinitis but is also useful in the follow up of patients and evaluation the efficacy of treatment. ${ }^{14}$ In general, numbers of eosinophils tend to be lower in perennial disease, in contrast to seasonal disease and depends on the level of seasonal allergen exposure. ${ }^{15,16}$ Allergic rhinitis is considered to be male predominant diseases, in this study there was a mild predominance for males. Although the onset of allergic rhinitis can occur at any time of life, $70 \%$ of these develop it before 30 years of age and in this study mean age were years $33.73 \pm 10.23$ years of age. In spite of new techniques for allergic rhinitis diagnosis, still nasal smear specifically for eosinophilia has some role either in diagnosis or treatment evaluation. ${ }^{17,18}$ The diagnosis of allergy in allergic rhinitis, is a difficult challenge and requires careful and broad analysis. This is due to both the diversity of the symptoms of the disease and absence of specific and reliable laboratory tests. Despite the fact that nasal cytology is a simple, non-invasive, repetitive, and cheap method, its use in medicine is relatively rare. Cytological examination of nasal mucosa has a long history. Most of the research papers had paid attention to the presence of eosinophils and their relation to the allergy, and the first of them had been conducted more than a century ago by Gollash in patients with asthma. ${ }^{19}$ Then, in the twentieth century, Eyermann has proven the presence of eosinophils in $72 \%$ out of 92 patients with rhinitis. ${ }^{20}$ Malmberg and Holopainen demonstrated the correlation between nasal eosinophilia and allergic rhinitis. ${ }^{21}$ Relationship between allergic rhinitis and nasal eosinophilia has been also studied by Kajosaari and Saarinen. In this survey, a group of 178 patients with allergic rhinitis was observed; the presence of eosinophils and mast cells in cytograms obtained from the nasal mucosa (using nasal smear taken by wiping the mucosa with a cotton-tipped applicator) was an important indicator of allergic rhinitis, characterized by a high specificity but a low sensitivity. ${ }^{22}$ Nowacki et al, analyzed the usefulness of cytology of the nasal mucosa in predicting the occurrence of allergic rhinitis. It has been shown that eosinophilia in nasal cytology, of at least $8 \%$, was associated with a high risk of developing AR. Therefore, it has been proposed that the increased nasal eosinophilia can be taken as an indicator of the risk of allergic march. The average percentage of eosinophils at baseline was significantly higher in allergic rhinitis patients. ${ }^{23}$ The present study has determined the correlation of allergic rhinitis with the degree of eosinophilia. As a positive test, 
A smear was considered positive for eosinophilia with at least more than five eosinophils in each high power field of microscopic slide. By analyzing individual studies evaluating the problem of eosinophilia in the cytological picture, one can see the differences in the very definition of the term "significant eosinophilia." This range is wide and it is ranging from $4 \%$ of all cells in Miller et al, Vaidya et al, found eosinophilia in at least $5 \%$ of these cells in the cytogram. $^{24,25}$

A similar analysis was made by Miller et al, however assuming $4 \%$ as a criterion for eosinophilia. In their work, the sensitivity of the study in allergic rhinitis was $70 \%$, with a specificity of $94 \% .{ }^{24}$ In the Bakhshaee et al, study, eosinophilia diagnosis was assessed as a highly specific $(88.5 \%)$ but less sensitive $(51.3 \%)$ in the cytological examination of the nasal mucosa in patients with $\mathrm{AR}$, with eosinophil counts of at least $10 \%$ number of cells in the smear. ${ }^{1}$

\section{CONCLUSION}

Based on the results of the study, the presence of eosinophil in nasal cytology is a good indicator of the likelihood of allergic rhinitis and in combination with other diagnostic tests leading to proper diagnosis. Nasal cytology with eosinophilia assessment can be a useful tool for early diagnosis of allergic rhinitis patients. Nasal cytology with allergic rhinitis is a helpful diagnostic test, usefulness of nasal cytology is limited due to the low sensitivity of the method and this inexpensive tool can be used for cost effective analysis of different drugs used commonly for the treatment of allergic rhinitis. It is worth emphasizing that until now, there have not been established any standards for testing and analysis of samples and that there is no consensus defining the value of "significant eosinophilia" in the nasal cytology.

\section{ACKNOWLEDGEMENTS}

Authors would like to thank to Dr. Ghaisas Virendra, Professor and Head of the department, Dr. Parab Sapana, Dr. Mane Santosh the faculty at the Department of ENT for allowing them to conduct study. Also, would like to thank to Mrs. Raje Swati, Assistant Professor, Department of Community Medicine who has provided valuable input for statistical and cost effectiveness analysis.

Funding: No funding sources

Conflict of interest: None declared

Ethical approval: The study was approved by the Institutional Ethics Committee

\section{REFERENCES}

1. Bakhshaee M, Fereidouni M, Farzadnia M, Varasteh AR. The Nasal Smear for Eosinophils, Its Value, and Its Relation to Nasal Mucosal Eosinophilia in Allergic Rhinitis. Iranian Journal of Otorhinolaryngology. 2010 Jul 1;22(3):73-8.
2. Varney VA, Jacobson MR, Sudderick RM. Immunohistology of the nasal mucosa following allergen- induced rhinitis: Identification of activated $\mathrm{T}$ lymphocytes, eosinophils and neutrophils. Am Rev Respir Dis. 1992;146:170-6.

3. Chanda R, Aggarwal AK, Kohli GS, Jaswal TS, Gupta KB. Comparative study of nasal smear and biopsy in patients of allergic rhinitis. Indian J Allergy Asthma Immunol. 2002;16(1):27-31.

4. Canakcioglu S, Tahamiler R, Saritzali G, Alimoglu Y, Isildak H, Guvenc MG, et al. Evaluation of nasal cytology in subjects with chronic rhinitis: a 7-year study. 2009;30(5):312-7.

5. Lopert R, Lang DL, Hill SR. Use of pharmacoeconomics in prescribing research. Part 3: cost-effectiveness analysis-a technique for decisionmaking at the margin. Journal of clinical pharmacy and therapeutics. 2003 Jun 1;28(3):243-9.

6. Wallace DV, Dykewicz MS, Bernstein DI, BlessingMoore J, Cox L, Khan DA, et al. The diagnosis and management of rhinitis: an updated practice parameter. Journal of allergy and clinical immunology. 2008 Aug 1;122(2):S1-84.

7. Pentewar GS, Wagh RJ, Chincholkar AS. Pharmacoeconomic assessment and comparing efficacy between cetirizine, levocetirizine, loratadine and fexofenadine in allergic rhinitis patients. Int $\mathbf{J}$ Basic Clin Pharmacol. 2017;6:2684-9.

8. Wright AL, Holberg CJ, Martinez FD, Halonen M, Morgan W, Taussig LM. Epidemiology of physiciandiagnosed allergic rhinitis in childhood. Pediatrics. 1994;94:895-901.

9. Meltzer EO. The prevalence and medical and economic impact of allergic rhinitis in the United States. J Allergy Clin Immunol. 1997;99:805-28.

10. Dykewicz MS, Fineman S, Skoner DP. Diagnosis and management of rhinitis: Complete guidelines of the joint task force on practice parameters in allergy, asthma and immunology. American Academy of Allergy, Asthma, and Immunology. Ann Allergy Asthma Immunol. 1998;81:478-518.

11. Howarth PH. Eosinophils and rhinitis. Clin Exp Allergy. 2005;5:55-63.

12. Lim MC, Taylor RM, Naclerio RM. The histology of allergic rhinitis and its comparison to cellular changes in nasal lavage. Am $\mathrm{J}$ Resp Crit Care Med. 1995;151:136-44.

13. Tveld CD, Garrelds IM, Koenders S, Vanwijk RG. Relationship between nasal hyperactivity, mediators and eosinophils in patients with perennial allergic rhinitis and controls. Clin Exp Allergy. 1996;26:9038.

14. Jirapongsananuruk O, Vichyanond P. Nasal cytology in the diagnosis of allergic rhinitis in children. Ann Allergy Asthma Immunol. 1998;80(2):165-70.

15. Salib R, Lau L, Howarth PH. Nasal lavage fluid concentrations of eotaxin-1 in naturally occurring allergic rhinitis: Relationship to disease activity, nasal luminal eosinophil influx, and plasma protein exudation. Clin Exp Allergy. 2005;35(8):995-1002. 
16. Wilson SJ, Lau L, Howarth PH. Inflammatory mediators in naturally occurring rhinitis. Clin Exp Allergy. 1998;28:220-7.

17. Pignatti P, Pala G, Pisati M, Perfetti L, Banchieri G, Moscato G. Nasal blown secretion evaluation in specific occupational nasal challenges. Int Arch Occup Environ Health. 2010;83(2):217-23.

18. Canakcioglu S, Tahamiler R, Saritzali G, Alimoglu Y, Isildak $\mathrm{H}$, Guvenc $\mathrm{MG}$, et al. Evaluation of nasal cytology in subjects with chronic rhinitis: A 7-year study. Am J Otolaryngol. 2009;30(5):312-7.

19. Gollash H. Zur kenntnis des asthmatischen sputums. Fortschritte der Medizin. 1889;7:361-5.

20. Eyermann CH. Nasal manifestation of allergy. Annals of Otology. 1927;36:808-15.

21. Malmberg H, Holopainen E. Nasal smear as a screening test for immediate-type nasal allergy. Allergy. 1979;34:331-7.

22. Kajosaari M, Saarinen UM. Evaluation of laboratory tests in childhood allergy. Total serum IgE, blood eosinophilia and eosinophil and mast cells in nasal mucosa of 178 children aged 3 years. Allergy. 1981;36(5):329-35.

23. Nowacki Z, Neuberg J, Strzałka K. Is prediction of the allergic march possible on the basis of nasal cytology? Pneumonologia i Alergologia Polska. 2010;78(4):26370.

24. Miller RE, Paradise JL, Friday GA. The nasal smear for eosinophils. Its value in children with seasonal allergic rhinitis. Ame $\mathrm{J}$ of Dis of Childr. 1982;136(11):1009-11.

25. Vaidya KA, Pai S, Nagaraj TS. A study on utility of nasal smear examination in diagnosing allergic rhinitis and its histopathological correlation in allergic nasal polyps. Int J of B and App Med Scien. 2015;5(1):2917.

Cite this article as: Pentewar GS, Wagh RJ,

Chincholkar AS. Assessment of cost effectiveness of antihistaminics in allergic rhinitis patients in rural region by Nasal cytology: a simple and inexpensive tool. Int J Basic Clin Pharmacol 2018;7:1083-8. 